\title{
The effects of passive tobacco smoking on the microcirculation of the abdominal wall in rats $^{1}$
}

\author{
Paulo Sandler ${ }^{\mathrm{I}}$, Bernardo Mastella ${ }^{\mathrm{II}}$, Diego Uchôa ${ }^{\mathrm{III}}$, Geraldo Pereira Jotz ${ }^{\mathrm{IV}}$, Henrique Záchia Leão ${ }^{\mathrm{V}}$, Leandro Totti Cavazzola ${ }^{\mathrm{VI}}$ \\ DOI: http://dx.doi.org/10.1590/S0102-865020160110000002 \\ IMD, Department of Surgery, Hospital de Clínicas de Porto Alegre (HCPA), Universidade Federal do Rio Grande do Sul (UFRGS), Porto Alegre-RS, \\ Brazil. Conception and design of the study, critical revision. \\ IUndergraduent student, School of Medicine, HCPA, UFRGS, Porto Alegre-RS, Brazil. Acquisition, analysis and interpretation of data; technical \\ procedures; manuscript preparation. \\ IIIPhD, Department of Pathology, HCPA, UFRGS, Porto Alegre-RS, Brazil. Histopathological examinations, critical revision. \\ ${ }^{\mathrm{IV}} \mathrm{PhD}$, Postgraduate Program in Health Sciences, Universidade Federal de Ciências da Saúde de Porto Alegre (UFCSPA). Morphological Sciences \\ Department, UFRGS, Porto Alegre-RS, Brazil. Conception and design of the study. \\ ${ }^{v}$ DHSc, Postgraduate Program in Health Sciences, UFCSPA. School of Medicine, Universidade Luterana do Brasil (ULBRA), Canoas-RS. \\ Morphological Sciences Department, UFRGS, Porto Alegre-RS, Brazil. Conception and design of the study. \\ ${ }^{V} \mathrm{PhD}$, Department of Surgery, Hospital de Clínicas de Porto Alegre (HCPA), Universidade Federal do Rio Grande do Sul (UFRGS), Porto Alegre-RS, \\ Brazil. Scientific, intellectual, conception and design of the study; analysis and interpretation of data, critical revision, final approval.
}

\section{ABSTRACT}

PURPOSE: To analysis the effects of passive smoking on the microstructure of tissues of the abdominal wall regarding microcirculation, using histopathological study of the tobacco exposed rats.

METHODS: Twenty four male Wistar rats were divided in Control Group (CG $=8$ animals) and Exposition Groups (EG $=16$ animals). EG was exposed to cigarette smoke 4x/day for 120 days, while CG was preserved from exposure. Food, water and housing were similar for both groups. After 120 days, urine samples were collected before necropsy to analyze cotinine levels (ng/mL) in urine and blinded histopathological analysis of the abdominal wall performed to count arteries and veins in dermal and muscular fascia layer.

RESULTS: No difference in weight was observed between both groups $(\mathrm{P}>0.05)$. Cotinine concentration was significantly higher in EG $(\mathrm{P}<0.05)$. In dermal layer, the average of vessels per animal was 8.72 (IC95\%: 8.31-9.13) for CG and 11,23 (IC95\%: 10.09-12.38) for EG. In muscular fascia layer the average of vessels per animal was 17.97 (IC95\%: 15.79-20.15) for CG, whereas the average for EG was of 14,85 (IC95\%: 12.71-17.01) $(\mathrm{P}<0.05)$.

CONCLUSION: Exposition to passive smoking may cause increase in the number of vessels in dermal layer, with the opposite effects at the muscular fascia layer.

Key words: Tobacco Products. Abdominal Wall. Smoke Inhalation Injury. Physiopathology. Rats. 


\section{Introduction}

The role of cigarette smoking is well established for many diseases, making this habit the leading cause of preventable death in the world ${ }^{1}$.

There are many clinical trials and meta-analyses showing that smokers who underwent surgical events had more post operatory complications comparing to non smokers or smokers who had a bigger cessation time before and after surgery ${ }^{1-4}$.

Studies suggest that the products of cigarette smoke may cause changes in the microstructure of tissues secondary to microcirculatory deficiency, oxygen concentration, tissue healing mechanisms, inflammatory process and others. This could predispose one who is undergoing surgery to complications such as infections, necrosis, delayed or anomalous wound healing, incisional hernia, among others ${ }^{4-6}$. Black et al. ${ }^{7}$ used human skin grafts to show that the presence of short-term nicotine amplified the concentration-dependent dermal vasoconstrictor effect of norepinephrine (NE) and attenuated endothelium-dependent skin vasorelaxation induced by acetylcholine in NE-preconstricted skin vasculature, without affecting endothelium-independent vasorelaxation induced by nitroglycerine in NE-preconstricted dermal vasculature. Similar results were reaffirmed by Ijzerman et al. ${ }^{8}$.

Among the postoperative complications in abdominal wall surgery, the wound infection is one of the most feared, as it changes the normal recovery of tissue layers, leading to occurrence of incisional hernia in almost $50 \%$ of its cases, generating augmented costs, number of hospital readmissions and hospital stay $^{9,10}$.

Dermal and subcutaneous tissue infections are clearly associated with the presence of ischemia of the skin layers involved ${ }^{11-13}$. Kool et al. ${ }^{14}$ states that cigarette smoking, apart from increasing systemic blood pressure and heart rate, also reduces dermal circulation when in short-term.

In the present study, the effects of cigarette smoke products in the microstructure of the tissues of the abdominal wall will be assessed regarding its microcirculation.

\section{Methods}

The present study was approved by the Ethics Committee on Animal Use (CEUA) of the Universidade Federal do Rio Grande do Sul (UFRGS), under protocol $n^{\circ} 19.127$ and the Ethics Committee on Animal Use on Animal Use (CEUA) of the Universidade Federal de Ciências da Saúde de Porto Alegre (UFCSPA).

Twenty-four male Wistar rats (Rattus norvegicus) were randomly divided into two groups: Exposition Group $(\mathrm{EG}=$ 16 animals) and Control Group ( $\mathrm{CG}=8$ animals). The number of animals for this type of experiment has been statistically validated. The exposure of the animals to passive cigarette smoke was induced according to previous experimental protocols, as it follows ${ }^{15-17}$.

The animals in EG were placed in plastic boxes, measuring approximately $30 \times 40 \mathrm{~cm}^{3}$ (four per box), with a wire mesh platform to access food and water. The boxes containing the animals were transferred to a laminar flow hood (CQ 800, Union Equipment Laboratorial $\left.{ }^{\circledR}\right)$, measuring $60 \mathrm{~cm}$ x $80 \mathrm{~cm}$, with a 20 $\mathrm{cm} \times 20 \mathrm{~cm}$ pyramid-shaped exhaust type ${ }^{18}$.

The concentration of $\mathrm{CO}$ in the exhaust hood was adjusted according to previous protocols (CO concentration between 100$130 \mathrm{ppm})$. The hood had a single overhead outlet and the airflow was passive, with an average temperature of $22{ }^{\circ} \mathrm{C}$ and average umidity of $60 \%$.

The concentration of particulate smoke was measured with a nephelometer (DustTrakII ${ }^{\circledR}$, model 8532, serial number $8.53 \mathrm{E}+09)$, with a tube including a $2.4 \mu \mathrm{g} / \mathrm{m} 3 /$ per minute air filter. This device was used from five minutes after onset of exposure until cycle completion.

Over a period of 120 days, from the $12^{\text {th }}$ after birth, the animals were exposed daily to the smoke generated by 16 lit cigarettes (four cigarettes in each session, with four sessions a day, at $8 \mathrm{~h}, 12 \mathrm{~h}, 16 \mathrm{~h}$ and $20 \mathrm{~h}$ ). Each session lasted 20 minutes, while cigarette combustion lasted 10 minutes on average. When not in sessions, the animals which had not yet been weaned were placed together with their mothers.

The smoke was administred in the absence of the mother until the pups were weaned (at 21 days), to avoid contaminating the breast milk. During exposure, the boxes containing EG were transferred to a laminar flow hood with four cigarettes in combustion. The ambient smoke (inside the hood) dissipated passively through the extract vent on the exterior. We used commercial filter cigarettes with the following composition: 10 $\mathrm{mg}$ of tar, $0,8 \mathrm{mg}$ nicotine and $10 \mathrm{mg}$ carbon monoxide.

The animals from CG were housed in two open boxes in the same room as the animals exposed to secondhand smoke, 5 meters away from the hood. The animals from both groups had free access to water and food. 


\section{Analysis of cotinine levels}

Exposure of animals to cigarette smoke was assessed by urinary concentrations of cotininte_(biomarker of tobacco passive consumption). Urine samples were collected at the end of exposure (120 days) by suprapubic aspiration while the animals were under anesthesia, immediately before euthanasia. The cotinine levels were quantified using high performance liquid chromatography (HPLC) according to the protocol established by Ceppa et al. ${ }^{19}$. Necropsy: After 120 of exposure, following all the protocols required by Resolution $n^{\circ} 1000$ of the Federal Council of Veterinary Medicine, all animals suffered euthanasia using the appropriate intraperitoneal dose of ketamine (75-90 $\mathrm{mg} / \mathrm{kg})^{18}$ and xylazine $(10 \mathrm{mg} / \mathrm{kg})$, with injection of $1000 \mathrm{IU}$ of heparine (Cristália, Brazil) at the left ventricle of the heart. Using a peristaltic pump, the animals were perfused with $200 \mathrm{~mL}$ of saline solution, followed by $200 \mathrm{~mL}$ of $4 \%$ paraformaldehyde (Reagan, Brazil) diluted in phosphate $0.1 \mathrm{M}$ "buffer" solution (pH 7,4, PBS), at room temperature.

\section{Histological processing}

Two fragments of abdominal wall were removed. The fragments removed should contain all layers of the abdominal wall, from peritoneum to epidermal layer, and measure about 4.0 $\mathrm{cm}^{2}$. Next, the samples were fixed in $10 \%$ buffered formalin and later processed and embedded in paraffin. From paraffin blocks, $4.0 \mu \mathrm{m}$ thick sections were cut using a microtome (Leitz), then deparaffinized. Histological sections were then stained using hematoxylin and eosin technique $(\mathrm{H} \& \mathrm{E})$. The slides were examined using an Olympus BX41 microscope (Japan), together with an Olympus DP73 camera (Japan).

The fragments were carefully placed in paraffin and cut transversely in relation to the abdominal wall to allow the simultaneous microscopic observation of all tissue layers of the abdominal wall from skin to peritoneum. Thus, all possible histopathological changes in each layer can be described separately, such as edema, hyperemia, acute inflammation, chronic inflammation, angiogenesis foci, hyperplasia, atrophy, degeneration and pigmentation changes.

\section{Pathological analysis}

The vessel counting was performed by an experienced pathologist, blinded in relation to the study groups, who randomly selected four high-power fields (x400) of each area to be studied in each section (Figure 1). In each high-power field a vessel counting was performed separately, yielding four different counts. Arterioles were not considered separatedely, and therefore were counted along with veins.

This four high-power fields counting was conducted in two distinct areas of the abdominal wall: one at the dermal layer and another one next to muscular fascia. Thus, each animal, both in the control group as in the exposure group, received two separate counts.

\section{Statistical analysis}

A Poisson regression was performed in order to compare differences in vessel numbers in two groups of animals for both dermis and fascia. Thus, each animal studied received two separated countings, both in the control group as in the exposure group.

\section{Results}

At the end of the experiment the analysis of animal weight showed no significant differences between EG $(376.4+52.8 \mathrm{~g})$ and CG $(363.2+35.8 \mathrm{~g})(\mathrm{P}=0.532)$. Moreover, analysis of the urinary cotinine concentration in the rats from the EG $(4.72+0.89 \mathrm{ng} / \mathrm{ml})$ was significantly higher than the concentration in CG $(0.65+0.12$ $\mathrm{ng} / \mathrm{ml})(\mathrm{P}=0.0001)$.

Exposure to the particulate smoke, measured by the nephelometer, showed an average exposure of $98.4 \mu \mathrm{g} / \mathrm{m}^{3}$, between the sixth and tenth minute of exposure, $86.6 \mu \mathrm{g} / \mathrm{m}^{3}$, between the eleventh and fifteenth minute of exposure and an abrupt fall to 2.8 $\mu \mathrm{g} / \mathrm{m}^{3}$ in the last five minutes of exposure.

In the layer of the dermis (Figure 2), the average number of vessels per animal was 8.72 (95\% CI: 8.31 - 9.13) in CG and 11.23 (95\% CI: $10.09-12.38)$ in $\mathrm{EG}(\mathrm{P}<0.05)$.

In the layer of fascia (Figure 3), CG showed an average of 17.97 (95\% CI: 15.79 - 20.15) vessels, while EG showed an average of 14.85 (95\% CI: 12.71 - 17.01) vessels in the same region $(\mathrm{P}<0.05)$. 


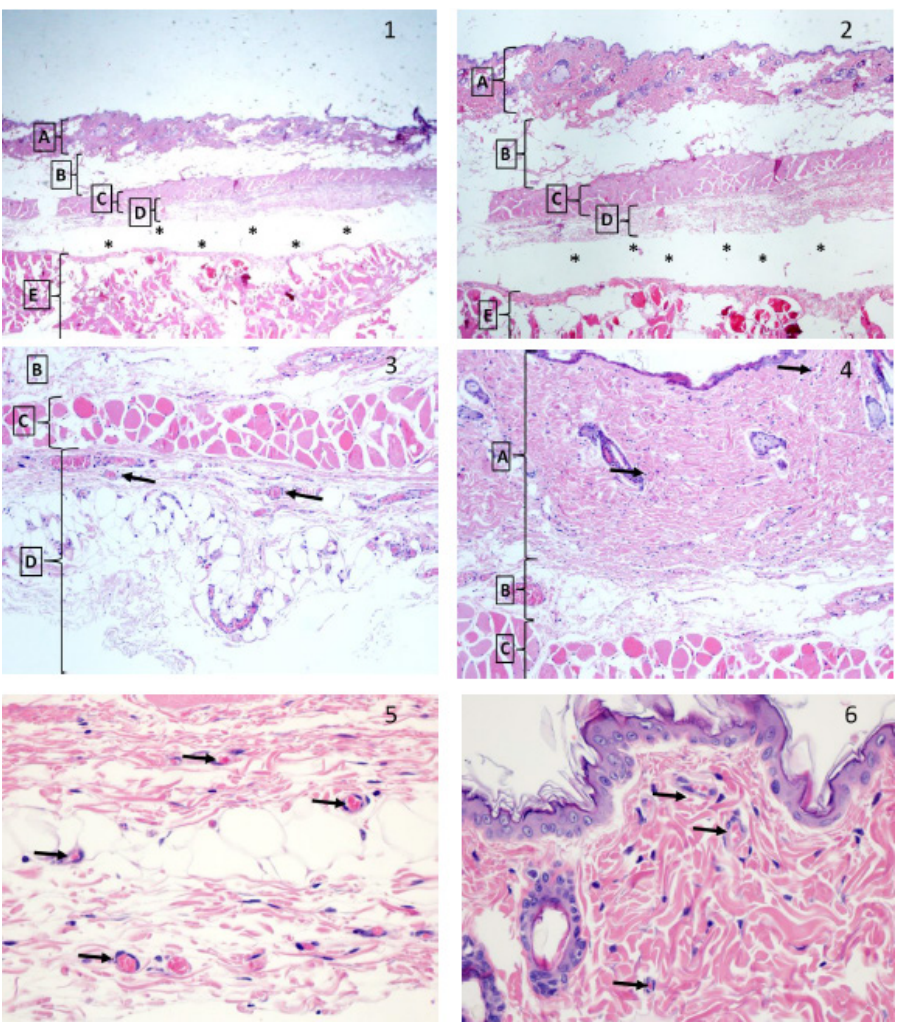

FIGURE 1 - Histological analysis of the abdominal walls of some of the animals used in the study (HE staining). The images illustrate the method used to define the exploited area, in increments of $12.5 \mathrm{x}$ (1), x40 (2), $\mathrm{x} 100$ in the fascia area and derma ( 3 and 4, respectively) and x400 in the region of fascia and dermis ( $\mathbf{5}$ and $\mathbf{6}$, respectively). Random areas were selected at $\mathrm{x} 400$ of the laminas, in both regions, to perform the vessel counting (arrows). Key A: derma region; Key B: Hipoderma; Key C: panniculus carnosus; Key D: Fascia; Key E: muscle of the abdominal wall; Asterisks: artifact region between the fabric layers.

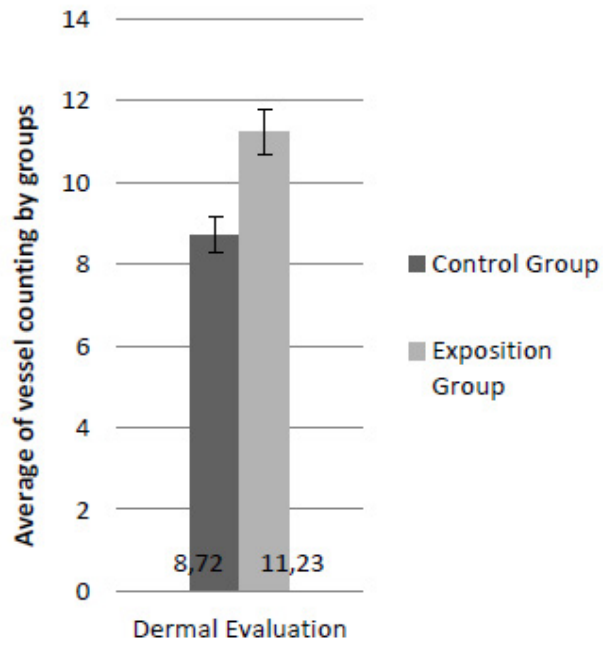

FIGURE 2 - Graphic showing the average of vessel counting at dermal layer, divided by groups (CG and EG). The average of vessel counting for EG is statistically superior than the average of vessel counting for CG for this tissue layer.

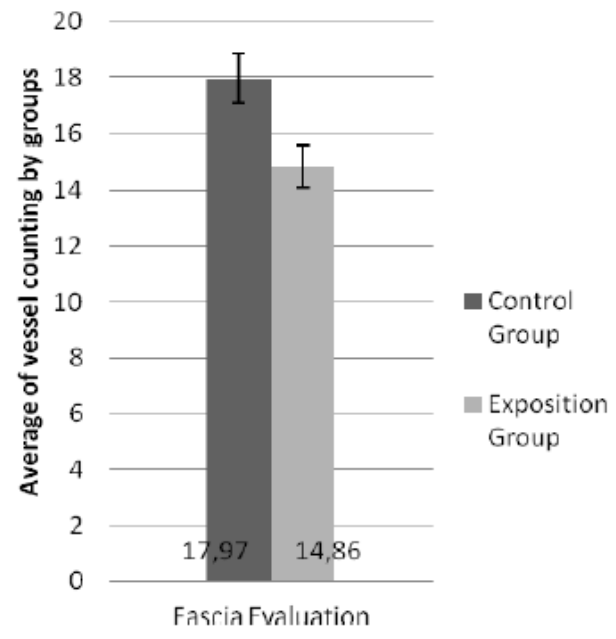

FIGURE 3 - Graphic showing the average of vessel counting at fascial layer, divided by groups (CG and EG). The average of vessel counting for EG is statistically superior than the average of vessel counting for CG for this tissue layer.

\section{Discussion}

The relationship between cigarette smoking and postoperative complications is well established in the literature, such as infection of surgical wound (SW), graft necrosis or incisional hernias ${ }^{2-5,20}$. Soresen et al. ${ }^{21}$ reports that smoking is associated with SW infection at all types of surgery, with an odds ratio (OR) of 2,95 for SW infections in light smokers and an OR of 3,46 for heavy smokers. A similar association was found regarding skin flap necrosis and epidermolysis after simple mastectomy and modified radical mastectomy. Patients who smoked until the date of the surgery compared to nonsmoker patients or smokers who started using nicotine patches or placebo prior to the surgery. On the other hand, a short period of abstinence is sufficient to reduce the risk of infection ${ }^{22}$.

Among the mechanisms affected by cigarette smoking that lead to disorders in wound repair, we can point to decreased blood flow by vasoconstriction in small cutaneous vessels.

Several studies have pointed out this phenomenon in cutaneous circulation, either by Doppler ecography of smokers ${ }^{4}$ or by flow study of skin flaps ${ }^{12}$. As a result, the tissue oxygenation and aerobic metabolism will be adversely affected ${ }^{12}$.

The hypoxia caused by this decreased flow is identified as a major trigger for the transcription of angiogenic factors ${ }^{22,23}$, including the hypoxia-induced factor 1 (HIF-1). This transcription factor, as expressed by its name, is induced by low oxygen tension. HIF-1 is degraded under normal oxygen concentrations, 
but stabilized in low concentrations, activating the transcription of several genes, including vascular endothelial growth factor (VEGF) and flt-1, its receptor.

Morimoto et al. ${ }^{24}$ demonstrated, using animal models, that the use of nicotine at low concentrations, such as those released in patches, is associated with significantly greater repairs in the same time period than their respective controls that were not exposed to any substance. However, higher levels of nicotine, similar to those obtained with the use of cigarettes, showed a poorer wound healing comparing to control.

Based on previously established review, it appears that our findings are supported by the literature. Knowing that the cigarette has a pivotal role in wound healing dysfunction, our previously expectations before analyzing the data was that the number of vessels would be decreased in the EG in relation to our control, both in dermis and fascia. However, the findings in dermal layer pointed in the opposite direction to show a higher average of vessels in animals exposed to smoke than their control peers.

From this observation, we speculate that this finding may be the result of the effects of hypoxia and products they originate, as the HIF-1. In addition, the angiogenic effects of nicotine, which occur by stimulation of nicotinic acetylcholine receptors ${ }^{25,26}$ can be concurrent responsible for this significant increase in the amount of exposed vessels in the dermis layer.

To interpret this finding based on what is known from literature about the relationship of cigarette and wound healing, one can conjecture that cigarette smoking increases the number of vessels as an adaptation to a state of hypoxia by chronic exposure to smoking. However, as this is a post mortem analysis of a healthy tissue, it is suggested that although angiogenesis occurs, it is not the determining factor for a proper healing, probably because it is not able to completely restore normal oxygen tension. Other consequences of tobacco use should lead to a poor healing even with increased vascularization.

From the best of our knowledge, our study is the first one to analyze angiogenesis and cigarette smoking by direct vessel counting in dermal and muscular fascia layer. Other studies used other kinds of biomarkers that support our findings, even though do not use the same method. Morimoto et al. ${ }^{24}$, uses immunohistological staining of von Willebrand to analyze newly formed capillaries in the wound bed of its rats. Heeschen et al. ${ }^{25}$ stated that nicotine at low concentrations promotes arteriogenesis using capillary density.

Some of the findings of this study however remain unclarified. As the number of vessels in the dermal layer is significantly greater in EG, the fascia also has shown significant difference to an opposite direction. The literature research made for this study has not found any explanation for this finding, nor any evidence that this could lead to poor wound healing. Further studies are necessary to determine the quality of this angiogenesis in the exposed animals, to evaluate if this response restores tissue vascularization properly.

Even so, this study contributes to the understanding of the phenomena consequent on the use of cigarette, contributing to the knowledge about its effects on regeneration and wound healing.

\section{Conclusions}

Histopathological analysis of abdominal wall of Wistar male rats exposed to passive cigarette smoke showed an increased number of vessels in dermal layer and a decreased number in vessels of muscular fascia layer when compared to control rats.

Although we have not found any other study that used the same vessel counting analysis as we did to compare the results, many other ways to assess microvasculature corroborates with our findings. Our findings may show an impaired vascular response to ischemic effects caused by nicotine, unable to restore normal blood flow, which ultimately could lead to impairments in surgical wound repair.

\section{References}

1. Wein RO. Preoperative smoking cessation. Arch Otolaryngol Neck Surg [Internet]. 2009 Jun;135(6):597-601. PMID: 19528409.

2. Mills E, Eyawo O, Lockhart I, Kelly S, Wu P, Ebbert JO. Smoking cessation reduces postoperative complications: a systematic review and meta-analysis. Am J Med. 2011 Feb;124(2):144-54.e8. PMID: 21295194.

3. Sørensen L. Wound healing and infection in surgery: the clinical impact of smoking and smoking cessation: a systematic review and meta-analysis. Arch Surg. 2012 Apr;147(4):373-83. PMID: 22508785.

4. Freiman A, Bird G, Metelitsa AI, Barankin B, Lauzon GJ. Cutaneous effects of smoking. J Cutan Med Surg. 2004 Nov-Dec;8(6):415-23. PMID: 15988548.

5. Aköz T, Akan M, Yildirim S. If you continue to smoke, we may have a problem: Smoking's effects on plastic surgery. Aesthetic Plast Surg. 2002 Nov-Dec;26 (6):477-82. PMID: 21222097.

6. Karlsson J. Quit smoking and reduce surgical complications. Knee Surg Sports Traumatol Arthrosc. 2011 Mar;19(3):331-2. PMID: 21222097.

7. Claire E. Black, Ning Huang, Peter C. Neligan, Ronald H. Levine, Joan E. Lipa, Steven Lintlop, Christopher R. Forrest, Cho Y. Pang. Effect of nicotine on vasoconstrictor and vasodilator responses in human skin vasculature. Am J Physiol Regul Integr Comp Physiol. 2001 Oct;281(4):1097-104. PMID: 11557615.

8. Ijzerman RG, Serne EH, van Weissenbruch MM, de Jongh RT SC. Cigarette smoking is associated with an acute impairment 
of microvascular function in humans. Clin Sci (Lond). 2003 Mar;104(3):247-52. PMID: 12605581.

9. Lamber B, Grossi J, Manna B. May polyester with collagen coating mesh decrease the rate of intraperitoneal adhesions in incisional hernia repair? Arq Bras Cir Dig. 2013 Jan-Mar;26 (1):13-7. PMID: 23702864.

10. Marcelo Bentacor Lontra, André Vicente Bigolin, Ricardo Gonçalves da Costa, João Vicente Grossi, Priscila Scalco, Sérgio Roll, TCBC-SP, Leandro Totti Cavazzola, TCBC-RS. Effectiveness of the combined use of lactic acid film and polypropylene mesh in the formation of intraperitoneal adhesions--an experimental model in rats. Rev Col Bras Cir. 2010 Oct;37(5):364-9. PMID: 21181003.

11. Leow Y-H, Maibach HI. Cigarette smoking, cutaneous vasculature and tissue oxygen: an overview. Skin Res Technol. 1998 Feb;4(1):18. PMID: 27331841.

12. Lars Tue Sørensen, Stig Jørgensen, Lars J. Petersen, Ulla Hemmingsen, Jens Bülow, Steffen Loft, Finn Gottrup. Acute effects of nicotine and smoking on blood flow, tissue oxygen, and aerobe metabolism of the skin and subcutis. J Surg Res. 2009 Apr;152(2):224-30. PMID: 18468640.

13. Smith JB, Fenske NA. Cutaneous manifestations and consequences of smoking. J Am Acad Dermatol. 1996 May;34(5 Pt 1):717-32. PMID: 8632065.

14. Kool MJF, Hoeks APG, Struijker Boudier HAJ, Reneman RS, Van Bortel LMAB. Short and long-term effects of smoking on arterial wall properties in habitual smokers. J Am Coll Cardiol. 1993 Dec;22(7):1881-6. PMID: 8245343.

15. Kozma R de LH. Modelo experimental de indução de enfisema pulmonar por exposição à fumaça de cigarro. Biblioteca Digital de Teses e Dissertações da Universidade de São Paulo; 2013.

16. Gairola CG, Drawdy ML, Block AE, Daugherty A. Sidestream cigarette smoke accelerates atherogenesis in apolipoprotein E -/mice. Atherosclerosis. 2001 May;156(1):49-55. PMID: 11368996.

17. Valenti VE, Abreu LC, Saldiva PH, Carvalho TD, Ferreira C. Effects of sidestream cigarette smoke exposure on baroreflex components in spontaneously hypertensive rats. Int J Environ Health Res. 2010 Dec;20(6):431-7. PMID: 21161804.

18. Henrique Zaquia Leão, Claudio Galleano Zettler, Eduardo Cambruzzi, Marcelo Lammers, Paula Rigon da Luz Soster, Fernanda Bastos de Mello, Guilherme Reghelin Goulart, Deivis de Campos, Geraldo Pereira Jotz. The Effects of passive smoking on laryngeal and tracheal mucosa in male wistar rats during growth: an experimental study. J Voice. 2016 Jan; pii: S0892-1997 (15) 003100. PMID: 26825467.

19. Rahman A, Hoffman NE. High-performance liquid chromatographic determination of famotidine in urine. J Chromatogr. 1988 Jul;428(2):395-401. PMID: 2905703.

20. Wein RO. Preoperative smoking cessation. Arch Otolaryngol Head Neck Surg. 2009 Jun;135(6):597-601. PMID: 19528409.

21. Sørensen LT, Hørby J, Friis E, Pilsgaard B, Jørgensen T. Smoking as a risk factor for wound healing and infection in breast cancer surgery. Eur J Surg Oncol. 2002;28(8):815-20. doi: 10.1053/ ejso.2002.1308.
22. Shweiki D, Itin A, Soffer D, Keshet E. Vascular endothelial growth factor induced by hypoxia may mediate hypoxia-initiated angiogenesis. Nature. 1992 Oct 29;359(6398):843-5. PMID: 1279431.

23. Shweiki D, Neeman M, Itin A, Keshet E. Induction of vascular endothelial growth factor expression by hypoxia and by glucose deficiency in multicell spheroids: implications for tumor angiogenesis. Proct Natl Acad Sci U S A. 1995 Jan 31;92(3):76872. PMID: 7531342.

24. Morimoto N, Takemoto S, Kawazoe T, Suzuki S. Nicotine at a low concentration promotes wound healing. J Surg Res. 2008 Apr;145(2):199-204. PMID: 17644111.

25. Heeschen C, Weis M, Cooke JP. Nicotine promotes arteriogenesis. J Am Coll Cardiol. 2003 Feb 5;41(3):489-96. PMID: 12575981.

26. Heeschen C, Jang JJ, Weis M, Pathak A, Kaji S, Hu RS, Tsao PS, Johnson FL, Cooke JP. Nicotine stimulates angiogenesis and promotes tumor growth and atherosclerosis. Nat Med. 2001 Jul;7(7):833-9. PMID: 11433349.

\section{Acknowledgements}

To Antonio Generoso Severino, and Clovis Tadeu Bevilacqua Filho for their technical assistance; the students Cilomar Martins de Oliveira Filho, Pedro Henrique Duarte Marks, and Victor Hugo Vargas Bittencourt for the help during the experiments.

\section{Correspondence:}

Leandro Totti Cavazzola

Departamento de Cirurgia, Hospital de Clínicas de Porto Alegre

Universidade Federal do Rio Grande do Sul

Rua Ramiro Barcelos, 2350

90035-903 Porto Alegre - RS Brasil

cavazzola@gmail.com

cavazzola@hotmail.com

Received: July 18, 2016

Review: Sep 19, 2016

Accepted: Oct 17, 2016

Conflict of interest: none

Financial source: none

${ }^{1}$ Research performed at Basic Health Sciences Institute (ICBS), Universidade Federal do Rio Grande do Sul (UFRGS), Porto Alegre-RS, Brazil. Part of Master degree thesis, Postgraduate Program in Surgery, UFRGS. Tutor: Leandro Totti Cavazzola. 